\title{
A PHC, A PSICOLOGIA HISTÓRICO-CULTURAL, A HISTORIOGRAFIA DA ALFABETIZAÇÃO BRASILEIRA E OS NEXOS PARA UM PROBLEMA DE PESQUISA
}

\author{
Rosângela Fernandes Torres ${ }^{1}$ \\ Arminda Rachel Botelho Mourão2
}

\begin{abstract}
RESUMO
O artigo tem por objetivo estabelecer os nexos entre a epistemologia marxista, a teoria pedagogia histórico-critica/PHC, a psicologia histórico-cultural e a historiografia do processo de ensino-aprendizagem inicial da leitura e da escrita, a partir dos quais abordaremos o objeto eleito - a alfabetização. Para isto, utilizou-se a metodologia histórico-crítica no levantamento bibliográfico, seleção de estudos, leitura histórico-crítica, fichamento, esquema e escrita. O resultado do levantamento inicial indica que ocorre no cenário brasileiro uma disputa sobre o método ideal e, encontramos três teorias explicativos, tendo uma apresenta seu ponto alto a base biológica e duas a base cultural, contudo os resultados de alfabetização desfavoráveis pedem compreendê-la, especialmente nas regiões norte e nordeste considerando a sala de aula, iluminada por uma filosofia, epistemologia e metodologia voltada para a classe trabalhadora e que instigou o presente problema de pesquisa: se há uma alternativa histórico-crítica de alfabetização nos anos iniciais (1 e 2) na escola pública?
\end{abstract}

Palavras-chave: PHC. Psicologia Histórico-Cultural. Alfabetização. Historiografia.

\section{PHC, CULTURAL HISTORICAL PSYCHOLOGY, THE HISTORIOGRAPHY OF BRAZILIAN LITERACY AND THE NEXUS FOR A RESEARCH PROBLEM}

\begin{abstract}
The article aims to establish the links between Marxist epistemology, historicalcritical/PHC pedagogy theory, historical-cultural psychology and the historiography of the initial teaching-learning process of reading and writing, from which we will

\footnotetext{
1 Doutoranda do Programa de Pós-Graduação em Educação na Amazônia - PGEDA, Polo da Universidade Federal do Amazonas - UFAM; Professora da Secretaria Municipal de Educação e Cultura - SEMED/Manaus/Brasil; Grupo de Pesquisa: Gênero, Trabalho e Educação; Bolsista do Programa de Apoio à Pós-Graduação Stricto Sensu - POSGRAD, financiado pela Fundação de Amparo à Pesquisa do Estado do Amazonas-FAPEAM. Orcid iD: https://orcid.org/000-0002-024-4164. E-mail: rosaftorres2014@gmail.com

2 Doutora em Educação em História, Política, Sociedade pela Pontifícia Universidade Católica de São Paulo-PUC; Professora Titular Universidade Federal do Amazonas; Professora do Programa de Pós-Graduação em Educação na Amazônia - PGEDA, do Polo da
} Universidade Federal do Amazonas - UFAM-Brasil. Orcid iD: https://orcid.org/0000-0002-19409477. E-mail: arachel@uol.com.br
\end{abstract}


approach the object elected - literacy. For this, the historical-critical methodology was used in the bibliographical survey, selection of studies, historical-critical reading, notation, scheme and writing. The result of the initial survey indicates that there is a dispute over the ideal method in the Brazilian scenario and we find three explanatory theories, one of which presents its high point on the biological basis and two on the cultural basis, however the unfavorable literacy results ask to understand it, especially in the north and northeast regions considering the classroom, illuminated by a philosophy, epistemology and methodology aimed at the working class and which instigated the present research problem: if there is a historical-critical alternative to literacy in the early years ( 1 and 2 ) in public school?

Keywords: PHC. Historical-Cultural Psychology. Literacy. Historiography.

\section{APS, PSICOLOGÍA HISTÓRICA CULTURAL, HISTORIOGRAFÍA DE LA ALFABETIZACIÓN BRASILEÑA Y NEXO PARA UN PROBLEMA DE INVESTIGACIÓN}

\section{RESUMEN}

El artículo tiene como objetivo establecer los vínculos entre la epistemología marxista, la teoría histórico-crítica / pedagogía de la APS, la psicología históricocultural y la historiografía del proceso inicial de enseñanza-aprendizaje de la lectura y la escritura, desde el cual abordaremos el objeto elegido - la alfabetización. Para ello, se utilizó la metodología histórico-crítica en el levantamiento bibliográfico, selección de estudios, lectura histórico-crítica, notación, esquema y redacción. El resultado de la encuesta inicial indica que hay una disputa sobre el método ideal en el escenario brasileño y encontramos tres teorías explicativas, una de las cuales presenta su punto culminante en la base biológica y dos en la base cultural, sin embargo los resultados de alfabetización desfavorables piden entenderlo, sobre todo en las regiones norte y noreste considerando el aula, iluminada por una filosofía, epistemología y metodología dirigida a la clase trabajadora y que instigó el problema de investigación actual: si existe una alternativa histórico-crítica a la alfabetización en los primeros años. años ( 1 y 2) en la escuela pública?

Palabras clave: APS. Psicología histórico-cultural. Literatura. Historiografía.

\section{INTRODUÇÃO}

O tema do artigo versa sobre as escolhas para abordar a problemática da alfabetização como objeto de estudo, ocupada em responder se há uma metodologia para alfabetizar que estabeleça nexos entre filosofia, epistemologia e metodologia.

Dessa forma, permita relacionar as teorias convergentes, pela qual a prática possa atestar a teoria por meio da escola e da sala de aula e demonstre o desenvolvimento do psiquismo como fruto do ensino nas escolas públicas brasileiras. 
Tendo o objetivo de contribuir para a formação de professores alfabetizadores e, consequentemente para a classe trabalhadora que depende da escola para apropriar-se do patrimônio sociocultural acumulado pela humanidade e, experimentar humanizar-se, enquanto indivíduo, em oposição aos processos de depredação do desenvolvimento psíquico próprios das políticas neoliberais.

Para compor uma exposição lógica, o texto organiza-se em três seções: na primeira, fundamenta a PHC enquanto ciência pedagógica, na segunda, aborda a psicologia histórico-cultural em oposição ao construtivismo, e na terceira seção da historiografia da alfabetização e os modelos explicativos atuais, por fim as considerações finais que convergem a Pedagogia Histórico-crítica, a psicologia histórico-cultural e o modelo explicativo do interacionismo para abordar a alfabetização do homem amazônico.

\section{POR ENTRE OS FUNDAMENTOS DA PEDAGOGIA HISTÓRICO-CRÍTICA E AS BASES PARA A ALFABETIZAÇÃO COMO OBJETO DE INVESTIGAÇÃO}

É consensual entre os pesquisadores brasileiros no campo da educação, de que a pedagogia constitui-se a ciência da educação, que tem como objeto explicar o que é imprescindível para que os homens aprendam. Dissemelhante, das ciências naturais, pois ocupam-se dos fenômenos naturais, e de outro modo, mas também diferente, das ciências humanas em razão de dedicarem-se a produção cultural.

Assim, optou-se por uma pedagogia de base científica que possa ser atestada pela experiência empírica, e nela, conjugue estabelecer os nexos entre a filosofia, a epistemologia e a busca da explicação pormenorizada do desenvolvimento psíquico, ao mesmo tempo, sobre os modos, pelos quais o indivíduo toma posse dos elementos socioculturais por meio dos quais humaniza-se, dito de outro modo pela passagem do pensamento sincrético ao sintético.

Dentre outras, salta a pedagogia histórico-crítica/PHC, pois postula a educação como uma prática intencional e sistemática, de um lado, a PHC 
responde aos limites das pedagogias ${ }^{3}$ e, de outro, oferece uma alternativa ao superar por incorporação as críticas sobre a violência simbólica exercida pelo sistema de ensino ao replicar a cultura dominante ${ }^{4}$, e da escola como instituição que ressoa a ideologia do Estado burguês ao converter as desigualdade sociais em desigualdades culturais, que por sua vez sustentam a estrutura da sociedade brasileira estratificada em classes sociais em seus percursos formativos ${ }^{5}$.

Diante da vida em sociedade e dos problemas que se apresentam a cada tempo histórico, a exemplo da pandemia causada pela sars-cov-2 que provoca a COVID-19, e expõe a fratura social da desigualdade de lutar pela vida e pelo acesso as condições de saúde "[...] cabe (ao nosso ver) à educação, na perspectiva de a PHC identificar os problemas postos pela realidade, mediar sua superação, preservar a vida e construir uma nova humanidade" (ORSO, 2020, p. 4). Pedagogia para a qual "[...] a contribuição de Marx é fundamental. Quando se pensam os fundamentos teóricos da pedagogia histórico-crítica (...) trata-se de uma dialética histórica expressa no materialismo histórico" (SAVIANI, 2005, p. 141).

Desse modo, o materialismo histórico-dialético busca compreender e explicar as relações sociais e toma como ponto de partida "a produção material. (Onde) Indivíduos produzindo (trabalhando) em sociedade, portanto, a produção (e suas formas de objetivação) dos indivíduos [será] determinada socialmente (pelas relações sociais experimentadas)" (MARX, 1999, p. 25, grifo nosso). De acordo com Marx (2013, p. 21 1), "[...] o trabalho é um processo que participam o homem e a natureza, processo em que o ser

\footnotetext{
${ }^{3}$ Se na pedagogia tradicional a iniciativa cabia ao professor - que era, ao mesmo tempo, o sujeito do processo, o elemento decisivo e decisório - e se na pedagogia nova a iniciativa se desloca para o aluno - situando-se o nervo da ação educativa na relação professoraluno, portanto, relação interpessoal, intersubjetiva -, na pedagogia tecnicista o elemento principal passa a ser a organização racional dos meios, ocupando o professor e o aluno posição secundária, relegados que são à condição de executores de um processo cuja concepção, planejamento, coordenação e controle ficam a cargo de especialistas supostamente habilitados, neutros, objetivos, imparciais. A organização do processo converte-se na garantia da eficiência, compensando e corrigindo as deficiências do professor e maximizando os efeitos de sua intervenção (SAVIANI, 2009, p. 11-12).

${ }^{4}$ A reprodução publicada por Pierre Bourdieu e Jean-Calude Passeron em 1970.

5 A escola capitalista na França publicado por Baudelot e Establet em 1971.
} 
humano, com sua própria ação, impulsiona, regula e controla seu intercâmbio material com a natureza.

Nesse sentido, o fio que conduzirá a feitura da $\mathrm{PHC}^{6}$ reconhece a necessidade de o homem produzir a sua existência continuamente. Em que pesa o protagonismo do homem em adaptar a natureza a suas necessidades e, assim transformá-la por meio do trabalho, o que faz do homem um animal distinto dos outros animais.

Assim, o trabalho constitui-se uma ação intencional que fora previamente antecipada em nível mental que conduz a ação à sua finalidade. Por conseguinte, o trabalho é uma atividade eminentemente humana, intencional que subverte a natureza para atender a sua subsistência, visto que para sobreviver o homem inaugura o processo de transformação da natureza.

A existência do homem não é um simples dado da natureza, tão pouco uma dádiva natural, mas algo produzido pelo próprio homem por meio do trabalho como atividade criadora e transformadora. Assim, necessita produzir a sua existência e produzi-la continuamente dar-se num processo de formação - a origem da humanidade nasce com o trabalho, a educação, por sua vez, emerge da necessidade de aprendizagem das atividades de criar e transformar a natureza acumulada.

Ao trabalhar os homens criam um mundo de cultura, pois, a educação é um feito de seres humanos "ela é, ao mesmo tempo, uma exigência do e para o processo de trabalho, bem como é, ela própria, um processo de trabalho" (SAVIANI, 2005, p.12). Logo, há duas rubricas para o trabalho: material e imaterial. $O$ trabalho material implica em garantir a subsistência material mais imediata, enquanto, o trabalho não-material refere-se ao conjunto de saberes sobre a natureza e a cultura produzido pela humanidade, posto que o trabalho não-material requer do homem a apropriação do mundo e suas propriedades (ciência), do conjunto de valores sociais (ética), e dos signos (arte).

\footnotetext{
6 Saviani cita o texto contribuição à crítica da economia política (MARX, 1973, p. 228-237) no qual se inspira a Pedagogia Histórico-Crítica.
} 
Nesse sentido, a atividade educativa carrega uma concepção de mundo, de homem, de sociedade explícita ou implicitamente. A educação possibilita ao homem antecipar no plano mental (teorizar) como forma de orientar intencionalmente a prática educativa, nomeia-se pedagogia. Há diversas pedagogias, dentre as quais, a pedagogia histórico-crítica que concebe a educação como trabalho não-material pelo qual ocorre o processo de humanização à medida em que o processo de humanização ocorre sob uma base biofísica na qual [...] "o trabalho educativo é um ato de produzir, direta e intencionalmente, em cada indivíduo singular, a humanidade que é produzida histórica e coletivamente pelo conjunto dos homens" (SAVIANI, 2005, p.13).

A PHC revela que a humanidade no homem, em tela, constrói-se da síntese de múltiplas relações sociais pelas quais implica apropriar-se das objetivações humanas produzidas historicamente consagrado na passagem que Marx se opõem ao método hegeliano de que a consciência emana do espírito e pontua: "Não é a consciência dos homens que determina o seu ser; é o seu ser social que, inversamente, determina a sua consciência" (MARX, 1973, p. 29).

A vida material sobrepõe-se a vida espiritual à medida que imputa condicionantes no desenvolvimento da vida, social, política e intelectual. Ela constitui-se elemento chave para compreender a ruptura de um modo de produção e a emergência de outro, a exemplo, da ruína da produção feudal e a emergência do modo de produção capitalista. Como assevera Marx:

Em certo estádio do desenvolvimento, as forças produtivas materiais da sociedade entram em contradição com as relações de produção existentes ou, o que é a sua expressão jurídica, com as relações de propriedade no seio das quais se tinham movido até então. De formas de desenvolvimento das forças produtivas, estas relações transformam-se no seu entrave. Surge então uma época de revolução social (MARX, 1973, p. 29).

Ainda que hoje pareça provável que o capitalismo seja a única opção de conceber a vida material a ermo, vê-se a contradição entre as relações 
de produção sustentada pela propriedade privada dos meios de produção em contradição com as forças produtivas o que sugere (como nos mostra a história) a sua eminente superação por outra forma de conceber a vida material o que justifica o socialismo.

Tomar conhecimento das contradições da vida material, inerente ao conflito entre as forças produtivas sociais e as relações sociais de produção, pressupõem um trabalho educativo com vista a maturar as condições subjetivas, ainda que as condições objetivas não estejam prontas, e as transformações sociais em germe são fomentadas no interior da sociedade e não fora dela, posto que:

Uma organização social nunca desaparece antes que se
desenvolvam todas as forças produtivas que ela é capaz de conter;
nunca relações de produção novas e superiores se lhe substituem
antes que as condições materiais de existência destas relações se
produzam no próprio seio da velha sociedade. É por isso que a
humanidade só levanta os problemas que é capaz de resolver e
assim, numa observação atenta, descobrir-se-á que o próprio
problema só surgiu quando as condições materiais para resolver já
existiam ou estavam, pelo menos, em vias de aparecer (MARX, 1973,
p. 29).

O surgimento de uma nova sociedade sob outras bases, sem classes e sem estado requer a maturação das condições objetivas. Sendo assim, a Pedagogia histórico-crítica proposta por Saviani lança a proposta didáticometodológica a serviço da transformação social, por meio da escola e requer da mesma que "funcione bem" e, possa articular procedimentos eficazes em cinco momentos: a prática social, a problematização, instrumentalização, cartase e retorna à prática social. Conforme explica na pedagogia histórico-crítica quadragésimo ano: novas aproximações publicadas em 2019.

No entendimento de que a prática social configura o professor e aluno de forma diferenciada, separados pelo grau de domínio cultural, contudo, o professor municiado de uma compreensão sintética e, em certo grau relativa, pois, articula os conhecimentos e as experiências que ao serem inseridos numa prática pedagógica revelam-se: 
como uma dimensão da prática social [que] envolve uma antecipação do que lhe será possível fazer com alunos, cujos níveis de compreensão ele não pode conhecer no ponto de partida, senão de forma precária. Por seu lado, a compreensão do aluno é sincrética, uma vez que, por mais conhecimentos e experiências que detenham, sua própria condição de alunos implica uma impossibilidade, o ponto de partida, de articulação da experiência pedagógica na prática social de que participam (SAVIANI, 2019, p. 103).

Contudo, não é análogo à preparação dos alunos cujo protagonismo é do professor como explica a pedagogia tradicional, tão pouco atividade inserida no interesse do aluno como ocorre na pedagogia nova. Desse modo, a prática social constitui-se um momento comum a professor e alunos.

A problematização é o segundo momento em que professor e alunos identificam os problemas imputados pela prática social, a serem resolvidos e, - conhecimento imprescindível para dominar para a resolução dos problemas. Observa-se, dessa maneira "tanto da apresentação de novos conhecimentos por parte do professor (segundo passo da pedagogia tradicional) como da apresentação do problema como um obstáculo que interrompe a atividade dos alunos (segundo passo da pedagogia nova)" (SAVIANI, 2019, p. 103). Ao buscar identificar os problemas postos pela prática social, e quais problemas precisam ser resolvidos na esfera da prática social e que tipo de conhecimento é necessário ter domínio para fazê-lo.

O terceiro momento de instrumentalização discorre sobre a apropriação dos instrumentos teóricos e práticos indispensáveis ao "equacionamento" dos problemas elencados na prática social. Instrumentos produzidos e disponíveis pela história, requerem sua transmissão pelo professor de forma direta ou indiretamente. No entanto, "não coincide como a assimilação de conteúdos transmitidos pelo professor por comparação com conhecimentos anteriores, como propõe a pedagogia tradicional em seu terceiro passo, nem com a coleta de dados preconizada pelo terceiro passo da pedagogia nova" (SAVIANI, 2019, p. 103). 
A catarse sobrevém após apropriação dos instrumentos básicos e a expressão elaborada de um novo entendimento da prática social que se alçou. Refere-se à "incorporação dos instrumentos culturais" elevados a condição de subsídios ativos de transformação social. Ainda que não se confunda com a "generalização, como quarto passo da pedagogia tradicional, nem hipótese como quarto passo da pedagogia nova" (SAVIANI, 2019, p. 103).

No quinto e último momento os alunos escalam do nível de pensamento sincrético para o nível sintético e o professor que ao iniciar já se encontrava no nível sintético agora no fim do processo "cuja compreensão se torna mais e mais orgânica". Os alunos ao final ascendem ao nível do professor posto que expressa a natureza da relação pedagógica proposta pela PHC, "não é a aplicação, como na pedagogia tradicional nem a experimentação que acontece na pedagogia nova" (SAVIANI, 2019, p. 104). A cartase entendida como o ponto alto do processo educativo, uma vez que, permite que os alunos demonstrem uma compreensão elaborada da prática social no nível do professor, ou seja, um pensamento sintético.

Depreende-se que a PHC interpreta em seus momentos a educação como uma prática social educativa que age sobre os sujeitos da prática social inserida de tal modo, que "não transforma de modo direto e imediato e sim de modo indireto e mediato".

Ao buscar penetrar no interior dos processos pedagógicos e reconstruir suas características objetivas requer fazer uso de uma teoria mediada, que possa explicar como o fez a psicologia histórico-cultural que tomou o desenvolvimento do psiquismo com base nas relações sociais humanas, considerando uma unidade biofísica a ser melhor explicitado na próxima seção.

Logo, a escola desponta como o lugar especial da cultural na qual o professor, um adulto mediador que comporta uma experiência de cultura, exerce a função de vincular o conhecimento/aprendizagem/ensino ao patrimônio genérico da humanidade construído histórica e pelo conjunto dos homens. 


\section{AS PERSPECTIVAS: EPISTEMOLOGIA GENÉTICA E DA PSICOLOGIA HISTÓRICO- CULTURAL SOBRE O DESENVOLVIMENTO}

Trata-se nesta seção de confrontar as epistemologias de estofo biológico e cultural como forma de justificar a que melhor explica o desenvolvimento psíquico, tendo em vista uma breve gênese nas quais amparam-se a perspectiva construtivista e histórico-cultural. De um lado, a epistemologia construtivista sustentada pelo idealismo kantiano e o método positivista lógico-formal, do outro, a epistemologia histórico-cultural assentada pelo materialismo histórico-dialético, contudo, é preciso admitir:

[que] representam esforços na direção à compreensão dos fenômenos psíquicos em tempos de uma ciência hegemonicamente pautada em enfoques duais acerca dos fundamentos materiais e ideias do psiquismo humano, de cunho formal, lógico-positivista (MARTINS; MARSIGLIA, 2015, p. 08).

Ainda que a primeira alinhe-se à lógica formal positivista que se nutre

das explicações de natureza biológica em si, e a segunda perspectiva conduz suas formulações pela superação do binário biológico e social ao mencionar o desenvolvimento humano.

Vigotski apresenta em seu texto "O significado histórico da crise da psicologia: uma investigação metodológica" em 1927, ao localizar as fragilidades, expressa especialmente, pela forma dual que se aborda os substratos biológico e cultural como frações em separadas. E postula que o desenvolvimento do psiquismo ocorre sobre uma base biofísica, em tela, tendo como estofo de sustentação - o materialismo histórico-dialético.

Não obstante, Piaget dispôs-se a uma análise genética e útil a adaptação baseada na lógica formal para a qual o conhecimento é fruto de reflexões filosóficas e, busca apreender a realidade como um dado estático e parcial, na qual fraciona o objeto e orienta-se pelos princípios: identidade objetal, ausência de contradição e exclusão. Ainda que no decorrer de seus estudos mencione a importância do que chama de ambiente para referir-se a cultural. 
E noutro polo Vigotski, representante da escola soviética, mas não o único ${ }^{7}$, pendeu a uma análise das causas e nexos do desenvolvimento psíquico apoiada na síntese forjada entre o biológico e o social fundindo-os: biossocial que ao mesmo tempo é processo e produto marcado pela dialética, que por sua vez tem como objeto a realidade concreta, e dela, põe em relevo o movimento do real, a contradição e as mudanças fomentadas.

Novack (1993) reforça que a lógica da dialética salta da realidade concreta e alveja apreensão do movimento do real, da contradição e das mudanças acarretadas conforme discorrem os princípios basilares da totalidade, movimento e contradição. Com efeito, a lógica dialética expressa a síntese de múltiplas determinações, cujo fenômeno combina elementos ao mesmo tempo subordinados e interdependentes de modo que ao construir conhecimento sobre a realidade reputa considerar as partes que constituem o fenômeno.

De modo que ao construir conhecimento sobre a realidade reputa considerar as partes que constituem o fenômeno. Razão pela qual justifica o método dialético circunscrever o fenômeno como um todo único (†otalidade) ao encadear (movimento) e modificar (contradições), assim compreender um fenômeno requer admitir os condicionantes que o abarcam sem fragmentá-lo.

Por conseguinte, o princípio do movimento repercute o real em ininterrupto transformação e regeneração, de modo que o método dialético, admite incorporar a totalidade e luta de opostos, ao passo que requer discernir a forma como se movimenta e desenvolve. O fenômeno sendo apreendido em seu trânsito, tanto da descrição do seu estado atual, mas, particularmente, a maneira como chegou ao ponto atual e como poderá ser diferente.

\footnotetext{
7 Desenvolvem pesquisas sobre a formação de conceitos na criança, sistema de atividade coletiva, rede de atividades, as respectivas gerações, a primeira geração representada por Vigotski, a segunda geração por Leontiev, Davydov, e Engeström e a terceira geração Engeström.
} 
O ponto crucial que cinge os dois teóricos apoia-se, sobretudo, pelo descolamento do modelo explicativo do campo da biologia para explicar o desenvolvimento das estruturas cognitivas como fruto das interações entre o sujeito e objeto de conhecimento com fins adaptativos. Para Piaget Les formes élémentaires de la dialectique (1980) o desenvolvimento cognitivo ocorre da interação da

[...] relação cognitiva sujeito/objeto é uma relação dialética porque se trata de processos de assimilação (por meio de esquemas de ação, conceitualizações ou teorizações, segundo os níveis) que procedem por aproximações sucessivas e através dos quais o objeto apresenta novos aspectos, características, propriedades, etc. que um sujeito também em modificação vai reconhecendo. Tal relação dialética é um produto da interação, através da ação, dos processos antagônicos (mas indissociáveis) de assimilação e acomodação (PIAGET, 1980, p. 134).

Com efeito, um movimento pelo qual a assimilação apropria-se de um novo esquema e "constitui um processo comum à vida orgânica e à atividade mental, portanto, uma noção comum à fisiologia e à psicologia" (PIAGET, 1996, p. 47), enquanto a acomodação ocorre concomitante à assimilação e organiza os elementos novos aos esquemas anteriores disparada pelas exigências ambientais. Por fim, a equilibração caracterizada por uma passagem entre um estado cognitivo menor a um estado maior.

Para ilustrar a contribuição de Piaget sobre o mapeamento dos estágios do desenvolvimento intelectual que toma por base a aprendizagem como fruto da ação sobre o objeto, como forma de adaptação para alçar o equilíbrio8, recorremos aos seus estágios do desenvolvimento psíquico caracterizados por períodos bem delineados e expresso pelas funções de: conhecimento (relacionado a organização do pensamento lógico e a organização da realidade), representação (trata do significado e do significante) e afetivas (da relação com o outro distingue a anomia pela ausência de regras, da heteronomia pela imposição de regras e, por fim a autonomia moral ação que depende das regras internalizadas).

8 Piaget como biólogo utiliza termos do campo da biologia para explicar o desenvolvimento intelectual de humanos. 
A saber com relação ao desenvolvimento do psiquismo há distintos enfoques entre epistemologia genética de Jean Piaget e a psicologia histórico-cultural encabeçada por Vigotski, pois a primeira não apreende a complexidade do desenvolvimento do psiquismo em seu ponto de partida e ignora que a vida do homem ultrapassa a adaptação natural ao meio, e conecta-se a experiência sociocultural por meio da atividade/trabalho. Martins e Marsiglia (2015) acentuam que 0 trabalho assume a qualidade de transformar pelo intercâmbio entre o ser e o seu entorno, permitiu ao homem produzir sua existência material, e ao fazê-lo, produziu uma segunda natureza, a natureza social expressa pela cultura.

Para Duarte (2006), Piaget ainda que tenha tomado o trabalho em sua teoria, o fez para explicar seu modelo interacionista de assimilação e acomodação numa clara transposição de explicações biologizante das relações entre todos os seres vivos e o meio. Radicalmente oposta à Piaget, a perspectiva teórico-metodológica marxista, inaugurada por Vigostski para o qual o desenvolvimento dar-se em sobre uma base, de natureza biológica e de natureza cultural que integradas permite perceber o desenvolvimento com um forte laço sociocultural, e aduz:

[...] a lei básica do desenvolvimento das funções psíquicas superiores: toda função psíquica superior no desenvolvimento da criança vem à cena duas vezes: a primeira com atividade coletiva, social, ou seja, como função interpsíquica; a segunda, como atividade individual, como modo interior de pensamento da criança, como função intrapsíquica (VIGOSTSKI, 2004, p. 483).

Demarca que desenvolvimento psíquico perpassa por crises nas quais uma estrutura precisa ruir para emergir outra, não sendo eliminada, mas incorporada a etapa ulterior fruto da interação cultural e social a qual o signo desempenha um papel importante. Facci (2004), defende o emprego de signo como divisor entre os modos de funcionamento naturais próprios do processo evolutivo e comuns aos animais superiores e homens, e os modos instrumentais produtos de uma evolução historicamente humana relativos à cultura. A aprendizagem requer um par mais desenvolvido que possa vincular o conhecimento traduzido pelos signos e significados, assim, a 
educação em sua forma escolar emerge nos dizeres de Martins e Marsiglia (2015) como:

\begin{abstract}
Ato mediado por signo[s] [que por seu turno] provoca profundas transformações no psiquismo humano, modificando profundas transformações no psiquismo humano, modificando radicalmente a relação sujeito-objeto, ou a resposta do sujeito aos estimulo do meio [social/escola] (MARTINS; MARSIGLIA, 2015, p. 21).
\end{abstract}

Dessa forma, entende-se que é imprescindível transmitir às novas gerações, o legado que os seres humanos acumularam e conquistaram ao longo da história humana, por meio da atividade social: o trabalho. Assim, desenvolver ao máximo o psiquismo para que possam usufruir do "patrimônio humano-genético exitosamente fazendo das apropriações mediações entre os sujeitos e a realidade" (MARTINS; MARSIGLIA, 2015, p. 30). O que justifica compreender a alfabetização a partir dessa perspectiva histórico-crítica, a seguir recorre-se a historiografia para situá-la.

\title{
3 A ALFABETIZAÇÃO NA CENA BRASILEIRA: DOS RECORTES AOS MOMENTOS HISTÓRICOS E, POR FIM AOS MODELOS EXPLICATIVOS SOBRE O SENTIDO DA ALFABETIZAÇÃO
}

O acesso à alfabetização pela classe trabalhadora e, consequentemente para a escolarização básica, situa-se em um cenário macro da política brasileira marcado por uma elite conservadora e seus desdobramentos, a exemplo das políticas de alfabetização que historicamente são importadas de um contexto externo a realidade brasileira, sendo apropriada e replicada em meio às diferentes realidades brasileiras marcadas pela pobreza. Somada a concentração de tecnologia e ciência no Centro-Oeste brasileiro, desta região reverte-se para as demais regiões do país as formas de apropriação do conhecimento que chegam estilhaçadas ao considerarmos o contínuo centro-periferia.

Assim, a desigualdade econômica naturaliza a desigualdade cultural, dentre elas, num primeiro plano superado o acesso à escola, contudo, defronta-se com outro obstáculo a relativa qualidade da escola oferecida a classe trabalhadora. 
No campo da alfabetização a literatura estável em termos históricos (MORTATTI, 2019) examina os métodos em seus passos/caminho/marcha sem, contudo, deixar de apreender a tensão dialética expressa pelas rupturas, permanências e semelhanças que perpassam cada novo/revolucionário método em detrimento do antigo/tradicional. Em seguida toma-se sua "querela" para visualizar o enfrentamento da alfabetização, e seu nexo com a escolarização e, desta, com o projeto de nação reclamado a cada momento histórico.

Segundo Mortatti (2007) a história da alfabetização apresenta seu reverso mais visível por meio da "querela dos métodos" e, para tal tece uma digressão sobre a história dos métodos de alfabetização, sobretudo, com relação a fase inicial da escolarização divide em quatro momentos "cruciais", cada um assinala um "novo" sentido ao ensino inicial da leitura e escrita - alfabetização, e pontua quanto aos diferentes sentidos que respondem a depender do momento as urgências políticas, sociais e culturais do país.

O primeiro momento de 1876 a 1890 , disputa sobre a metodização do ensino da leitura entre os defensores do "novo" método da palavração e os que creditavam aos "antigos" métodos sintéticos que vai da parte para o todo: o alfabético usa a soletração e parte do nome das letras; o fônico parte dos sons correspondentes às letras; o silábico parte da emissão do som das sílabas. Prescreve-se assim, começar o ensino da leitura pela apresentação das letras e seus respectivos "nomes (método da soletração/alfabético), ou de seus sons (método fônico), ou das famílias silábicas (método da silabação)" dosando o grau de dificuldade do menor para o maior. Em seguida, juntada as letras ou os sons em sílabas as conhecidas famílias silábicas, "ensinava-se a ler palavras formadas com essas letras e/ou sons e/ou sílabas e, por fim, ensinavam-se frases isoladas ou agrupadas". No que diz respeito à escrita reservava-se "à caligrafia e ortografia, e seu ensino, à cópia, ditados e formação de frases, enfatizandose o desenho correto das letras" (MORTATTI, 2006, p.5). 
As cartilhas com base no método sintético entram em circulação no final do século XX, confeccionadas com base nas experiências de professores paulista e fluminenses são replicadas por vários estados durante muitas décadas.

A ruptura com os métodos sintéticos tem início com a publicação do poeta português João de Deus: a Cartilha Maternal ou Arte da Leitura, em 1876, a saber passa a ser divulgado pelo Antônio da Silva Jardim de modo sistemático e programático professor de português da Escola Normal de São Paulo, considerado por ele como método científico, definitivo e ponto basilar para o progresso social, distinto dos métodos sintéticos o "método João de Deus" ou "método da palavração". Importado de Portugal usa "princípios da moderna linguística da época e consistia em iniciar o ensino da leitura pela palavra, para depois analisá-la a partir dos valores fonéticos das letras" (MORTATTI, 2006, p. 6).

A disputa entre os que advogam o "método João de Deus" e os que permanecem na defesa dos métodos sintéticos (soletração, fônico e a silabação), estabelece a pauta de que o ensino da leitura remete à questão de como ensinar, pede um método, portanto, uma didática atrelada as contribuições da linguística vigente.

O segundo momento de 1890 a meados de 1920, marcado pela institucionalização do método analítico, disparado pela reforma Paulista da instrução pública a partir de 1890 com a aspiração de modelar outros estados alinhado à modernidade republicana industrial inspirada na Europa e Estados Unidos.

Expressa pela reestruturação da Escola Normal de São Paulo, seguida da criação do anexo Escola modelo, 1896, criou-se o Jardim de Infância donde jorrava as ações inspiradoras de "práticas" para professores tanto da capital e quanto do interior deveriam assimilar como modelo.

Sendo disseminado de um lado os valores industriais pela escolarização de mão de obra para o trabalho, e de outro uma nova concepção de infância e métodos de ensino, etc. difundida pelos escolanovistas, tornou-se obrigatória nas escolas públicas paulistas e 
replicada para outros estados por meio de "missões de professores" paulistas. "Embora a maioria dos professores reclamassem da lentidão de resultados desse método" (MORTATTI, 2006, p.7), a obrigatoriedade manteve-se até a proposta de "autonomia didática" posta na Lei 1750, de 1920 com a "Reforma Sampaio Dória".

O método analítico versa sobre o ensino da leitura ocorre do "todo", em seguida, analisa suas partes, a depender do que seus adeptos consideram "todo", parte-se da palavra, ou da sentença, ou da historieta. A disputa marcada agora pelas questões de didática entre os métodos tradicionais e analíticos e dentre esse último, a forma como conduzir o processo de ensino da leitura partindo da historieta como defendem os professores paulistas exige uma compreensão do leitor no ato de ler e impede que o ensino seja iniciado pela sentença ou conjunto delas, como propunham os professores paulistas exige uma compreensão do leitor no ato de ler e impede que o ensino seja iniciado pela sentença ou conjunto delas, como propunham os professores paulistas Theodoro de Moraes, Arnaldo de Oliveira Barreto e Carlos Antônio Gomes Cardim e partindo do conto (discurso) como advoga o professor fluminense João Köpke?, como explica Mortatti:

[..] defendia a necessidade de se iniciar o processo de ensino pelo conto (discurso), e não pela "historieta", como propunham os paulistas; privilegiava a análise do conto, que, por sua vez, deveria ser escolhido, não com a preocupação em manter o enfoque no ensino das sílabas e letras, mas em apresentar, por meio de gravuras e palavras correspondentes, ideias familiares que deveriam favorecer a aprendizagem da leitura e escrita e conduzir conscientemente à abstração (elementos da palavra: sílabas e letras); e propunha que o ensino tivesse como objetivo a leitura inteligente e expressiva, a qual exige uma compreensão do leitor no ato de ler e impede que o ensino seja iniciado pela sentença ou conjunto delas, como propunham os professores paulistas (MORTATTI, 2015, p.73).

A tensão ocorre com relação ao ensino da leitura e a escrita mantemse como algo em torno da caligrafia, do tipo de letra a ser utilizada, apoiada

\footnotetext{
9 In: MORTATTI, M. R. L. João Köpke (1852-1926) na história do ensino de leitura e escrita no Brasil. In: MORTATTI, M. R. L. et al. (Orgs.). Sujeitos da história do ensino de leitura e escrita no Brasil [online]. São Paulo: Editora UNESP, 2015, p. 59-75. ISBN 978-85-68334-36-2. Available from SCIELO Books.
} 
no treino por meio de cópia e ditado. Também emerge o termo "alfabetização" para designar o ensino inicial de leitura e escrita. Ao passo que a disputa pauta-se nas questões didáticas: como ensinar a criança; toma-se pôr a definição das habilidades visuais, auditivas e motoras, a quem ensinar; considerando a contribuição da psicologia e da linguística e como já dissemos a didática.

O terceiro momento a alfabetização sob medida ventilada pela "Reforma Sampaio Dória" que versa sobre a "autonomia didática" por meio da qual reforça a resistência dos professores a partir de meados de 1920 e germina novas buscas para solucionar os problemas relacionados ao ensino e aprendizagem da alfabetização.

Buscas que provocam a conciliação de métodos sintéticos e analíticos no que converge nos métodos mistos ou ecléticos, embora permaneça a disputa entre os defensores dos métodos sintéticos e analíticos acaba sendo diluída paulatinamente, ao passo que ganha força a tendência de relativização sobre a importância do método (num contínuo centro-periferia, considerando São Paulo o centro e outros estados a periferia), tendo a preferência circunscrita com mais ênfase pelo método global de contos.

A relativização dos métodos ocorre por conta da pesquisa de $M$. B. Lourenço Filho que lança luzes sobre os aspectos psicológicos que enfatizam o nível de maturidade biofisiológica e, sobrepuja, os aspectos linguísticos e pedagógicos, pois ocupa-se de investigar a "hipótese de um nível de maturidade como pré-requisito indispensável para o aprendizado da leitura e da escrita, das quais derivou o livro Testes ABC" (BERTOLETTI, 2015, p.175). O teste em questão é constituído de oito provas que mensuram o nível de maturidade que condicionam a aprendizagem da leitura e da escrita e subsidiam a composição de salas homogêneas de alfabetização, vistas como racionais e eficazes ao classificar as habilidades visuais, auditivas e motoras.

Contudo, permanecem os métodos mistos ou ecléticos endossados pelas cartilhas e inaugura a ideia e a prática de que é necessário um período para preparar para alfabetização. Instala-se um ecletismo sobre o 
processo e conceito de ensino na alfabetização e enlaça a métrica para compor as salas homogêneas. A escrita continua sendo considerada como objeto de apropriação da habilidade por meio da caligrafia e ortografia, sendo ensinada concomitante a leitura que abrangia exercitar a distinção e coordenação motora: visual, auditiva e corporal, dentre outras. Até o final da década de 1970 perdura a alfabetização sob medida, na qual a maturidade da criança ganha relevo e subordina a pauta didática à pauta psicológica.

\section{O quarto momento remonta ao construtivismo e a desmetodização da} alfabetização que data de meados de 1980 até os dias atuais, as disputas encabeçadas pelos partidários da "nova" perspectiva construtivista em detrimento dos "antigos" testes de maturidade e, ainda dos "antigos" métodos de alfabetização, tematizado o enfrentamento do fracasso da escola na alfabetização das crianças na busca por respostas ao problema corrente. O quadro abaixo remete as chamadas teorias explicativos ora denominado construtivismo, interacionismo e letramento.

Quadro 1 - Teorias explicativas: construtivismo, interacionismo e letramento

\begin{tabular}{|l|l|l|l|}
\hline Teorias & Precursores & Ponto Alto & Pesquisadores brasileiros \\
\hline Construtivista & Piaget & Biologia & Emília Ferreiro, Gross e outros \\
\hline Interacionista & Baktin e Vigotski & Cultura & Wanderlei e Smolka e outros \\
\hline Letramento & Chartier & Cultura & Magda Soares e outros \\
\hline
\end{tabular}

Fonte: Elaborado pela autora, 2021.

O construtivismo baseado na pesquisa sobre a psicogênese da língua escrita encabeçado pela Emília Ferreiro ganha adeptos e desloca o debate dos métodos de ensino para o processo do aprendiz (sujeito cognoscente) e pauta-se não como um método novo, mas como uma "revolução conceitual" e sugere "abandonarem-se as teorias e práticas tradicionais, desmetodizar-se o processo de alfabetização" (MORTATTI, 2006, p.10) e arremata junto a defesa da necessidade de uso das cartilhas e também dos testes de maturidade.

O construtivismo ganha hegemonia nos documentos oficiais a partir dos PCN's, passando a serem produzidos livros didáticos denominados 
construtivistas" ou "socioconstrutivista" ou "construtivistas interacionistas", que não eram suficientes para provocar $\circ$ apagamento das cartilhas tradicionais e nem seu uso por parte dos professores.

Ao passo que ocorre um momento crucial da alfabetização segundo Mortatti, emerge a perspectiva do interacionismo linguístico difundida pelos pesquisadores João Wanderlei Geraldi10 e Ana Luiza Smolka baseada no interacionismo linguístico, e na psicologia soviética, no qual o texto (discurso) é a unidade que congrega o sentido da linguagem e dele é o ponto de partida que possibilita um processo de interlocução entre professor e alunos, que por sua vez, rejeita o uso de cartilhas dada sua rigidez para o ensino da leitura e da escrita. Tal perspectiva preceitua que ao mesmo tempo em que se ensina a ler e a escrever, as crianças já estão lendo e produzindo textos escritos.

Tal perspectiva pede práticas sociais de leitura e escrita semelhante ao proposto por Freire para alfabetizar jovens e adultos a leitura e escrita que extrapola os muros da escola e toma o "mundo", e conecta-se aos múltiplos aspectos e constitui uma didática da leitura e da escrita que parte do texto. Assim, gera uma disputa entre nível hegemônico construtivista, interacionista, mas também convivem com os métodos mistos.

Faz parte ainda do quarto momento da história da alfabetização - o letramento, que em meados da década de 1980 remete a aquisição da leitura e da escrita e seu usos e funções sociais numa sociedade letrada, sendo incorporado pelos estudos sob a influência do termo literacy que no inglês significa pessoa letrada e educada sendo inicialmente traduzido por "alfabetização" e, atualizado por "alfabetismo". Destaca-se que o termo é difundido e usado sistematicamente após as publicações de Tfouni (1995), Kleiman (1995) e Soares (1995).

A defesa do termo letramento anuncia o esforço de pesquisadores brasileiros proporem uma nova forma de alfabetizar, entretanto, não gerou um consenso sobre seu uso, por outro lado, vê-se incorporado em discursos e

10 GERALDI, J. W. (Org.). O texto na sala de aula: leitura \& produção. Cascavel: Assoeste, 1984. No qual apresenta o ensino da Língua Portuguesa interacionista baseada no texto. 
práticas relacionadas à escolarização inicial e, que a disputa entre o letramento social, escolar e tradicional. E ainda no quarto momento a remedotização da alfabetização num movimento de retorno visto pela disputa em nível hegemônico entre o método fônico presente no discurso oficial instituído pela Política Nacional de alfabetização ${ }^{11}$, baseada nas noções de "evidências científicas" conforme esclarece Mortatti:

Esse novo paradigma para a alfabetização se fundamenta nas noções de "Evidence-based education" e "Literacy practice evidence-based", derivadas da "Evidence-based Medicine", e em resultados de pesquisas internacionais divulgadas em relatórios produzidos predominantemente a partir da década de 1960, por pesquisadores estadunidenses, ingleses, franceses, portugueses (MORTATTI, 2019, p. 42).

Nessa disputa pela hegemonia teórica no campo da alfabetização preconizada pelos documentos oficiais, atualmente sendo pautado pelo "novo paradigma fônico" PNA (2017) versus o construtivismo PCN'S (1998) e deste último como método alfabético-silábico, fora da disputa hegemônica normativa desponta o interacionismo, crescendo em termos de convencimento vem ganhando mais adeptos e pesquisadores, pois atestam seus achados pelas pesquisas em escolas públicas imersas em toda sorte de contradição.

Mediante o exposto, os sentidos da alfabetização são disputados na cena política e no interior do campo da educação tanto pelas pesquisas realizadas no espaço da escola pública quanto em espaços fora dela: o que pede interrogar os sentidos da alfabetização e seu projeto de nação e revelar segundo Mortatti (2000):

[...] opções temático-conteudísticas (o quê?) e estruturais-formais (como?), projetadas por determinado sujeito (quem?), que se apresenta como autor de um discurso produzido de determinado ponto de vista e lugar social (de onde?) e momento histórico (quando?), movido por certas necessidades (por quê?) e propósitos (para quê?), visando a determinado efeito em determinado tipo de leitor (para quem?) e logrando determinado tipo de circulação, utilização e repercussão (MORTATTI, 2000, p. 30).

11 Por meio do Decreto de $\mathrm{n}^{\circ} 9765$ de 11 de abril de 2019, do atual governo Jair Messias Bolsonaro. 
Na busca de qualificar o debate para engendrar formas de resistência faz-se mister questionar se a política representa os avanços em termos de pesquisa em alfabetização ou se revela disputas e ataques à escola pública, de um lado pelos mecanismos de privatização da gestão, do currículo e da oferta (ADRIÃO, 2009; 2016), de outro, no interior do campo da alfabetização a disputa pela pecha do "mais científico" com teorias que oferecem pouco lastro de pesquisa experimentada nas salas de aulas brasileiras.

E, por fim, ainda sem a pretensão de esgotar o debate, e aquecer o grupo daqueles que pesquisam na escola pública, para apreender as nuances da relação ensino-aprendizagem da leitura e da escrita nos anos iniciais de escolarização e, ainda, como forma de endossar a garantir o direito à educação como direito público subjetivo, bem como as mudanças ocorridas nas relações de trabalho que ressoam nas condições materiais objetivadas tanto de formação intelectual quanto de existência material tensionada pelo modelo econômico do capitalismo (MOURÃO, 2006) e sem nos furtar a crítica, e a partir dela fortalecer a escola para a classe trabalhadora, propomos o problema: é possível uma alternativa históricocrítica de alfabetização nos anos iniciais ( 1 e 2) na escola pública?

\section{CONSIDERAÇÕES FINAIS}

Coadunamos com a premissa de que a alfabetização refere-se ao processo de ensino-aprendizagem inicial da leitura e da escrita, e converge para os pressupostos da Pedagogia histórico-crítica à medida que prescreve a aprendizagem subordinada ao ensino. E, este último imbuído de intencionalidade que marca a existência do homem, pois a existência humana não é uma dádiva da natureza e, sim uma construção social metabolizada por meio do trabalho produzido pelos próprios homens.

Destarte, a contribuição da psicologia histórico-cultural versa sobre o postulado, de que aprendizagem é fruto das mediações culturais e sociais. Salta a importância da escola como um lugar especial da cultura que faz circular sistematicamente as contribuições da ciência e, assim antecipa o desenvolvimento e sobrepuja, a espontaneidade da natureza. 
No campo da alfabetização há um consenso sobre a importância de diferentes modelos explicativos que marca a disputa e a tensão próprias da tarefa científica. Dessa forma, convivem atualmente três modelos explicativos: o construtivismo, o letramento e o interacionismo. O construtivismo embora tenha sido largamente difundido na década de 1980 e gozado de hegemonia nos marcos legais (PCNs), mas não necessariamente nas práticas professorais. Ele desloca o debate do método de ensino para o cognoscente, para um aprendizado pautado em estágios biológicos.

Enquanto o letramento adota o termo literacy em inglês e interpreta a alfabetização baseada no processo de ensino que vislumbra a representação de fonemas em grafemas e grafemas em fonemas. Ao passo que considera alfabetização um processo de compreensão/expressão de significados por meio do código escrito, bem como, seus usos e funções sociais numa sociedade letrada.

E por fim, o modelo que melhor aproxima-se do presente estudo aponta para o interacionismo pelo diálogo com a psicologia históricocultural e a linguística em seu caráter dialético, cujo texto converte-se em discurso a ser produzido pelas crianças, sendo a linguagem o ponto de partida que possibilita a apropriação da língua portuguesa mediada pelo professor como um processo singular e irrepetível. E vislumbra a formação crítica sobre sua posição no mundo social e quiçá sua transformação.

Depreende que a alfabetização ao considerar a realidade cultural na qual a criança está imersa, para em seguida aproximá-la de seu desenvolvimento. Apoia-se no pressuposto de que toda criança não aprende espontaneamente, o que justifica a relevância social do papel do professor e da sua formação integral, mas vivencia esse processo de uma maneira única, primeiro num plano individual e, depois num plano social.

É mister estabelecer os nexos entre a pedagogia histórico-cultural, a psicologia histórico-cultural, o interacionismo no processo de alfabetização do homem amazônico, voltado para o ensino-aprendizagem da modalidade escrita, tendo como base a modalidade oral. Isto repele 
replicar um livro didático, ou um planejamento a ser executado pelo professor, ou ainda de passos rijos análogos a uma tarefa fabril, ou mesmo encarcerando a alfabetização nas relações grafofônicas.

Posto na atual política nacional de alfabetização (PNA) que elimina a complexidade que envolve a alfabetização, em termos de cultura, de linguagem e, de desenvolvimento. E posiciona a alfabetização e sua natureza como uma tarefa pouco sofisticada em termos de trabalho.

Mediante a historiografia da alfabetização brasileira pretende-se elaborar um saber científico que enlace uma concepção de mundo e de homem, uma teoria explicativa do desenvolvimento como fruto das mediações culturais e, das relações de produção social regional.

E por fim, sirva para fundamentar o trabalho imaterial que os professores alfabetizadores desenvolvem e, assim contribuir para a valorização da cultura amazônica, sobretudo, para a classe que sustenta esse país: a classe trabalhadora.

\section{REFERÊNCIAS}

ADRIÃO, T. et al. Grupos empresariais na educação básica pública brasileira. Educ. Soc., Campinas, v. 37, n. 134, p.113-131, jan./mar., 2016.

ADRIÃO, T. et al. Uma modalidade peculiar de privatização da educação pública: a aquisição de "sistemas de ensino" por municípios paulistas. Educação \& Sociedade [online]. 2009, v. 30, n. 108, p. 799-818. Disponível em: Epub 13 Maio 2010. Acesso em: 26 de Julho 2021. ISSN 1678-4626. https://doi.org/10.1590/S0101-73302009000300009.

BERTOLETTI, E. N. M. Lourenço Filho (1897-1970), escritor de e sobre literatura infantil e juvenil. In: MORTATTI, M. R. L. et al. (Orgs.). Sujeitos da história do ensino de leitura e escrita no Brasil [online]. São Paulo: Editora UNESP, 2015, p. 169-194. ISBN 978-8568334-36-2. Available from SciELO Books.

FREIRE, P. Ação cultural para a liberdade. $5^{a}$ ed., Rio de Janeiro: Paz e Terra, 1981.

GERALDI, J. W. (Org.). O texto na sala de aula: leitura \& produção. Cascavel: Assoeste, 1984.

MARTINS, L. M.; MARSIGLIA, A. C. G. As perspectivas construtivistas e histórico-crítica sobre o desenvolvimento da escrita. - Campinas: Autores Associados, 2015.

MARX, K. Contribuição para a crítica da economia política do capital. Lisboa: Estampa, 1973.

MARX, K. Para a crítica da economia política do capital: o rendimento e suas fontes. Tradução de Edgard Malagodi, Ed. Nova Cultural: São Paulo, 1999. 
MARX, K. O processo de trabalho e processo de produzir mais-valia. In: O capital: 0 processo de produção do capital. Vol. I. $31^{a}$ ed. - tradução de Reginaldo Sant'anna, Rio de Janeiro: Civilização Brasileira, 2013. p. 211-231. MORTATTI, M. do R. L.; FRADE, I. C. A. da S. (Org.). Alfabetização e seus sentidos: o que sabemos, fazemos e queremos? - Marília: Editora Unesp, 2014.

MORTATTI, M. R. L. Os sentidos da alfabetização: São Paulo - 1876/1994. São Paulo: Editora UNESP; Brasília: MEC/Inep/Comped, 2000.

MORTATTI, M. do R. L. Conferência proferida durante o Seminário "Alfabetização e letramento em debate", promovido pelo Departamento de Políticas de Educação Infantil e Ensino Fundamental da Secretaria de Educação Básica do Ministério da Educação, realizado em Brasília, em 27/04/2006.

MOURÃO, A. R. B. A empresa qualificante: construção possívelẹ In: A fábrica como espaço educativo. - São Paulo: Scortecci, 2006.

SAVIANI, D. Pedagogia histórico-crítica: primeiras aproximações. $9^{a}$ ed. Campinas: Autores Associados, 2005.

SAVIANI, D. Escola e democracia. $41^{a}$ ed. Campinas: Autores Associados, 2009.

SAVIANI, D. Pedagogia histórico-crítica: novas aproximações. Campinas: Autores Associados, 2019.

SCOCUGLIA, A. C. Histórias inéditas da educação popular: do sistema Paulo Freire aos IPMs da ditadura. João Pessoa: Ed. Universitária/UFPB; São Paulo: Cortez: Instituto Paulo Freire, 2001.

PIAGET, J. Les formes élémentaires de la dialectique. Ed. idées/Galimard: Suisse, 1980.

PIAGET, J. Biologia e conhecimento: ensaio sobre as relações entre as regulações orgânicas e os processos cognoscitivos. Petrópolis: Vozes, 1996.

NOVACK, G. Introdução à lógica marxista. Belém: Universidade Federal do Pará, 1993.

ORSO, P. J. O novo coronavírus, a pedagogia histórico-crítica, à sociedade de classes e o internacionalismo proletário. Revista Exitus, [S.I.], v. 10, n. 1, p. e020048, 2020. DOI: 10.24065/2237-9460.2020V10N1 1d1 1432. Disponível em:

http://www.ufopa.edu.br/portaldeperiodicos/index.php/revistaexitus/article/view/14 32. Acesso em: 18 ago.2021.

Recebido em: 24 de agosto de 2021.

Aprovado em: 29 de outubro de 2021. Publicado em: 04 de dezembro de 2021. 